\title{
MENSTRUAL REGULATION: AN ALTERNATE FOR INDUCED ABORTION
}

\author{
KHANOM R ${ }^{1}$, AKTER $\mathrm{S}^{2}$, NUR J ${ }^{3}$, KHATUN K ${ }^{1}$
}

\begin{abstract}
:
Objective: To assess the reason for seeking menstrual regulation among 500 clients, in 2 different hospitals.

Methods: This was a descriptive type of cross sectional study during the period of July, 2007 to January2008. The study was carried out in the Menstrual Regulation and Training Service Program (MRTSP) centre of Dhaka medical college hospital and Mymensingh Medical College Hospital. Total 500 patients irrespective of age, occupation, family status, religion who came for MR in the MRTSP centre in DMCH \& MMCH were included in the study.

Results: Regarding the place of residence, it was found that of the total 500 respondents $64.6 \%$ came from the urban area and rest from the rural area. The mean age of the respondents was 28.58yrs with 6.42 mean age of the husbands were 37.04yrs 6.42. Investigating the reasons for seeking $M R$, it was found that $74.4 \%$ reported that they had adopted MR because they did not want any more children.
\end{abstract}

Key words: Menstrual regulation, induced abortion, morbidity, mortality.

J Dhaka Med Coll. 2009; 18(1) : 25-27

\section{Introduction:}

M.R. (Menstrual Regulation) is the aspiration of endometrial content within 14+ days of missed period without knowing patient is pregnant or not ${ }^{1}$ It differs from abortion and other methods of pregnancy termination. MR can be performed without anesthesia or sedation by trained paraprofessionals as well as by physician on an out patient basis in about five to ten minutes.

Under the penal code of 1860, induced abortion was permitted only to save life of the mother. In 1972, the law waived for women raped during the liberation war. Abortion were performed in a few district hospital under the guidance of expert teams from Bangladesh, India and the United States of America. Bangladesh has officially accepted MR in 1975 as a legitimate health and family planning measure ${ }^{2}$.

In this capacity the availability of MR services can contribute directly to the reduction of female morbidity and mortality. It has important role in fertility control in over populated country. It also offers significant new opportunities for women to control safely and effectively the timing and number of child. MR is gradually replacing abortion done through quack. ${ }^{3}$ It is the basic right of women to have easy access to safe MR services ${ }^{4}$.

\section{Methodology:}

This was a descriptive type of cross sectional study, which was designed to assess the cause for seeking in Menstrual Regulation and Training Service Program (MRTSP) of Dhaka Medical College Hospital and Mymensingh Medical College Hospital. This study was conducted during the period from July 2007, to January 2008.

The total sample size was 500 . A formal written permission from the adviser of MRTSP center of $\mathrm{DMCH}$ and $\mathrm{MMCH}$ was taken before proceeding for data collection. After explaining the purpose of the study to the respondents and obtaining verbal consent, data were collected.

The collected data were checked and rechecked to exclude any error of inconsistency and then entered into the computer (SPSS) program. Analysis was done by using SPSS program.

1. Assistant Professor, Department of Obstetric \& Gynaecology, Dhaka Medical College \& Hospital, Dhaka.

2. Honorary Medical Officer, Department of Obstetric \& Gynaecology, Dhaka Medical College Hospital, Dhaka.

3. Assistant Professor, Department of Obstetric \& Gynaecology, Mymensingh Medical College \& Hospital, Mymensingh. 


\section{Results:}

Information were collected from 500 respondents of MR clients from MRTSP of DMCH and $\mathrm{MMCH}$. The results obtained were as follows:

Regarding the place of residence it was found that of the total 500 respondents, $(64.6 \%)$ came from urban area

The age of the respondents ranges from 16 to 46 yrs. They were categorized into 4 groups. Up to 20 yrs(14.4\%), 21-30 yrs(55.6\%), 31-40 yrs $(28 \%), 41-50$ yrs $(2 \%)$ respectively. The mean age 28.58 yrs with $\mathrm{SD} \pm 6.42$ (Table-I)

\section{Table-I}

Distribution of respondent and their husbands by age.

\begin{tabular}{lccccc}
\hline & \multicolumn{2}{c}{ Wife } & & \multicolumn{2}{c}{ Husband } \\
\cline { 2 - 3 } \cline { 5 - 6 } & Number & $\%$ & & Number & $\%$ \\
\hline Up to 20 years & 72 & 14.4 & & 00 & 00 \\
$21-30$ & 278 & 55.6 & & 104 & 20.8 \\
$31-40$ & 140 & 28.0 & & 262 & 52.4 \\
$41-50$ & 10 & 2.0 & & 125 & 25.0 \\
$51-60$ & 00 & 00 & & 9 & 1.8 \\
\hline Total & 500 & 100 & & 500 & 100 \\
\hline
\end{tabular}

Wife=mean 28.58yrsSD\#6.42. Husband=mean 37.04yrsSD\# 6.71 .

The age of the respondents' husbands in this study ranges between 25 to $56 \mathrm{yrs}$. They were categorized into 4 groups, in the age group of 21-30 yrs $(20.8 \%)$, $31-40$ yrs(52.4\%), 41-50(25\%), $51-60$ yrs(1.8\%) respectively. The mean age was 37.04 with the standard deviation \#6.71 years (Table-I)

Table-II

Reasons for seeking MR.

\begin{tabular}{lcc}
\hline Reasons & Number & $\%$ \\
\hline To delay pregnancy & 57 & 11.4 \\
No more child & 372 & 74.4 \\
Spacing of birth & 52 & 10.4 \\
Contraceptive failure & 19 & 3.8 \\
\hline Total & 500 & 100.00 \\
\hline
\end{tabular}

Table II shows the prime reasons for seeking menstrual regulation was not to want more child $(74.4 \%)$

\section{Discussion:}

The study was done with the objectives to assess the cause of seeking menstrual regulation among 500 clients in two different centers of Dhaka and Mymensingh. The study results revealed that majority $(64.76 \%)$ of the respondents came from urban area. The reasons for the relative paucity of rural woman could be location of the MRTSP centre which is out of reach of the rural people. Other causes may be positive knowledge and attitude towards safe termination etc.

The study findings show that most of the MR clients $(55.6 \%)$ were in the age group of $21-30$ years mean age was 28.58 years. One study showed that the mean age of the MR clients were 26 years ${ }^{4,5,6}$ and few other study results stated the mean age of the clients were 27 years ${ }^{7,8}$. This findings show that the MR clients are almost middle in their reproductive life and they have to use any family planning methods, either temporary or permanent, to avoid future pregnancy.

The respondents were asked to state why they have decided to undergo the MR procedure. The majority $(74.2 \%)$ of clients reported that they had adopted MR procedure because they did not want any more children about $11.4 \%$ clients mentioned that they went for MR to delay pregnancy, $10.5 \%$ for spacing of next birth (Table-II), it is surprising that only $3.8 \%$ of the respondents reported that they had accepted MR procedure because of contraceptive failure, although about $70 \%$ of them reported that they had used contraception before MR. There is a similarity with the researcher's findings Kabir et $\mathrm{al}^{9}$ states that more than half $(51.7 \%)$ of the clients reported that they had adopted MR because they did not want any more children. Nineteen and half percent mentioned they went for MR to delay the pregnancy and 19.6\% for spacing the next child.

It is likely that women do not want to become pregnant and yet have failed to make effective use of contraception would tend to accept MR to terminate an unwanted pregnancy. Women who practiced contraception effectively would not have pregnant and therefore would not require $M^{10}$ 


\section{Conclusion:}

The main reason for seeking M.R is not to want more child, so if we can increase the availability of other contraceptive methods then the rate of M.R. will decrease, though it is a safer procedure .

\section{References:}

1. Bhatla N. Anatomy. Jeffcoat's, Principles of Gynaegology. International edition, London. Arnold, 2001;697

2. Waliullah S and AL Sabir A. A study of Menstrual Regulation Programmed in two clinies. A Bibliography on Menstrual Regulation and abortion studies in Bangladesh, BIRPERHT. 1996; 3: 76-90.

3. Kabir SM. Cause and Consequences of unwanted pregnancy from Asian women's perspectives. International J Gynae Obstet. 1989; 7(3): 9-14.

4. Dixon- Mueller R. Innovations in Reproductive Health care, Menstrual Regulation Policies and
Programs in Bangladesh. Studies in Family Planning. 1988 (May/June) ;19 (3) : 129-140

5. Bureau of statistics. Selected basic facts about Bangladesh, Islam W, eds Statistical pocket book of Bangladesh, Dhaka. 1997; 3: 15-17.

6. Rashid K, M, Khabiruddin $\mathrm{M}$ and Hyder $\mathrm{S}$. NIPORT report, Population policy and program in Bangladesh. Text book of Community Medicine and Public Health. Dhaka, RKH publishers. 1999; 181-182.

7. Akhter et al Demographic pattern of MR, MR news letter, BAPSA. May 1995; 2: 25-29.

8. Bhuiyan $\mathrm{N}$, and Begum S. Experience with Menstrual Regulation and Family Planning services in Chittagong Medical College Hospital between October 92 to July 93. A bibliography on Menstrual Regulation and abortion studies in Bangladesh, BIRPERHT. 1996: 149-15.

9. Akhter $\mathrm{H}$ H. Abortion in Bangladessh. A bibliography on Menstrual regulation and abortion studies in Bangladesh, BIRPERHT. 2005:2

10. MR Newsletter BAPSA, Number-4, June 2004; 2028. 